\title{
Studi Perbandingan Kepuasan Pasien terhadap Mutu Pelayanan Keperawatan dan Faktor Determinan di Tiga Rumah Sakit
}

\author{
Reni Fitria ${ }^{1}$ \\ ${ }^{1}$ Fikes Undhari, 18 Koto Baru Dharmasraya \\ Correspondence email: renifitria4586@gmail.com
}

\begin{abstract}
Abstrak. Pendahuluan: Kepuasan pasien berhubungan dengan mutu pelayanan rumah sakit. Kepuasan merupakan salah satu indikator baik tidaknya suatu pelayanan dan salah satu akibat dari rendahnya kepuasan dapat dilihat dari jumlah kunjungan pasien ke rumah sakit setempat. Tujuan penelitian mengetahui perbedaan kepuasan pasien terhadap mutu pelayanan keperawatan pada Rumah sakit di Kota Padang. Metode: desain penelitian ini menggunakan studi komparatif dilakukan. Sampel dalam penelitian ini berjumlah 150 orang, dengan teknik quota sampling. Hasil: dari ketiga rumah sakit di dapatkan untuk Rumah Sakit $\mathrm{R}$ sebagian kecil (24\%) 12 responden mengatakan puas. Rumah sakit Y sebagian kecil (10\%) 5 responden mengatakan puas. Rumah sakit I sebagian kecil (10\%) 5 responden mengatakan puas. Hasil uji statistik didapatkan $p$-value $=0,000<0,05 \mathrm{Ho}$ di tolak, maka ada perbedaan kepuasan terhadap mutu pelayanan keperawatan di tiga rumah sakit kota Padang. Diskusi: Diharapkan perawat dalam memberikan pelayanan keperawatan kepada pasien lebih ditingkatkan dari lima dimensi: tangible, realibility, responsiveness, assurance, emphaty agar mutu pelayanan rumah sakit juga meningkat.
\end{abstract}

Kata kunci: kepuasan pasien; pelayanan keperawatan

Abstract. Introduction: Patient Satisfaction Is Related To The Quality Of Hospital Services. Satisfaction Is One Indicator Of Whether Or Not A Service Is Good And One Of The Consequences Of Low Satisfaction Can Be Seen From The Number Of Patient Visits To A Local Hospital. The Purpose Of The Study Was To Determine The Differences In Patient Satisfaction With The Quality Of Nursing Services In Hospitals In The City Of Padang. Method: The Design Of This Study Using Comparative Studies Was Carried Out. The Sample In This Study Amounted To 150 People, With A Quota Sampling Technique. Results: Of The Three Hospitals Obtained For R Hospital, A Small Percentage (24\%) Of 12 Respondents Said They Were Satisfied. Y Hospital Is Small (10\%) 5 Respondents Said They Were Satisfied. A Small Hospital (10\%) 5 Respondents Said They Were Satisfied. The Statistical Test Results Obtained P-Value = 0,000 <0,05 Ho Was Rejected, Then There Were Differences In Satisfaction With The Quality Of Nursing Services In The Three Hospitals In The City Of Padang. Discussion: It Is Expected That Nurses In Providing Nursing Services To Patients Will Be Improved From Five Dimensions: Tangible, Realibility, Responsiveness, Assurance, Empathy So That The Quality Of Hospital Services Also Increases

Keywords: Patient Satisfaction; Nursing Services

\section{PENDAHULUAN}

Kepuasan pasien berhubungan dengan mutu pelayanan rumah sakit. Dengan mengetahui tingkat kepuasan pasien, manajemen rumah sakit dapat melakukan peningkatan mutu pelayanan (Gillies, D.A 1994). Persentase pasien yang mengatakan puas terhadap pelayanan berdasarkan hasil survei dengan intrumen yang baku. Rata-rata hasil yang didaptkan dari beberapa Rumah Sakit di Indonesia menunjukkan 67\% pasien yang mengeluh adanya ketidakpuasan dalam penerimaan pelayanan keperawatan. (Nursalam, 2012)

Kota Padang merupakan ibukota provinsi Sumatera Barat yang memiliki 28 rumah sakit. Kota Padang sendiri memiliki delapan Rumah Sakit yang melayani pelayanan pendaftaran BPJS bagi masyarakat yang terdiri dari rumah sakit negri dan swasta. Sejak adanya pelayanan BPJS pasien yang berobat ke rumah sakit harus melalui alur dan ketentuan BPJS. Untuk itu pelayanan yang di berikan di rumah sakit harus di tingkatkan baik rumah sakit negri maupun swasta agar pasien sebagai penerima jasa merasa puas terhadap pelayanan yang diberikan rumah sakit (Profil Kesehatan Sumatera Barat, 2012).

Hasil survey awal yang dilakukan di Rumah sakit $\mathrm{R}$ didapatkan: dari 5 orang yang diwawancara Pasien /keluarga di dapatkan hasil untuk dimensi tangible puas $(70 \%)$ tidak puas $(30 \%)$, reliability puas $(60 \%)$ tidak puas $(40 \%)$, responsiveness puas $(60 \%)$ tidak puas $(40 \%)$, assurance puas $(40 \%)$ tidak puas $(60 \%)$, emphaty puas (70\%) tidak puas (20\%). (Profil RSUD Padang, 2014)

Hasil survey awal yang dilakukan di Rumah Sakit Y didapatkan: dari 5 orang yang diwawancara Pasien /keluarga di dapatkan hasil untuk dimensi tangiblepuas $(80 \%)$ tidak puas $(20 \%)$, reliability puas $(70 \%)$ tidak puas $(30 \%)$, responsiveness puas $(80 \%)$ tidak puas $(20 \%)$, assurance puas $(60 \%)$ tidak puas $(40 \%)$, emphaty puas (80\%) tidak puas (20\%). (Profil RS Yos, 2014)

Pada Rumah Sakit I didapatkan: dari 5 orang yang diwawancara Pasien /keluarga di dapatkan hasil untuk dimensi tangible puas $(70 \%)$ tidak puas $(30 \%)$, reliability puas $(60 \%)$ tidak puas $(40 \%)$, responsiveness puas $(80 \%)$ tidak puas $(20 \%)$, assurance puas $(60 \%)$ tidak puas $(40 \%)$, emphaty puas $(60 \%)$ tidak puas $(40 \%)$ (Profil RS Yarsi). Berdasarkan latar belakang diatas, maka peneliti merasa tertarik untuk melakukan penelitian studi perbandingan kepuasan pasien terhadap mutu pelayanan keperawatan di tiga Rumah Sakit di Kota Padang.

\section{METODE PENELITIAN}

Jenis penelitian yang digunakan adalah studi komparatif. (Nursalam, 2011) Lokasi penelitian dilakukan di tiga rumah sakit Rawat inap Rumah Sakit R, Rumah Sakit Y, Rumah Sakit I. Populasi dalam penelitian adalah pasien yang di rawat di ruangan rawat inap dewasa di Rumah Sakit R, Y, I pada saat melakukan penelitian. Sampel diambil dengan teknik quota 
sampling (Sopiyudin, 2012) sebanyak 150 responden untuk tiga rumah sakit sehingga masing-masing rumah sakit terdiri atas 50 responden. Hipotesis Alternatif : Ada perbandingan kepuasan pasien terhadap mutu pelayanan keperawatan di tiga rumah sakit kota Padang tahun 2014.

Analisis data menggunakan uji Chi-square (Arikunto, 2010). Sedangkan untuk melihat perbandingan kepuasan pasien terhadap mutu pelayanan keperawatan di rawat inap di Rumah Sakit $R$, Y, I menggunakan uji Kruskal Wallis karena data tidak berdistribusi normal. Dimana setelah dilakukan uji normalitas dengan sampel lebih dari 50 maka yang di baca Shapiro Wilk di dapatkan nilai $p=0.000$, karena nilai $p<0,05$ maka kesimpulan data tidak berdistribusi normal (Sopiyudin, 2012).

\section{HASIL DAN PEMBAHASAN}

Tabel 1. Hubungan Faktor Determinan Dengan Kualitas Pelayanan Keperawatan

\begin{tabular}{|c|c|c|c|c|c|c|c|c|c|c|c|c|c|c|c|}
\hline \multirow{3}{*}{ No. } & \multirow{3}{*}{$\underset{\text { determinan }}{\text { Faltor }}$} & \multicolumn{4}{|c|}{ RS Yos } & \multirow{3}{*}{$\begin{array}{c}\text { p- } \\
\text { value }\end{array}$} & \multicolumn{3}{|c|}{ RSUD } & \multirow{3}{*}{$\begin{array}{c}\text { p- } \\
\text { vahue }\end{array}$} & \multicolumn{4}{|c|}{ RS Yarsi } & \multirow{3}{*}{$\begin{array}{c}\text { p- } \\
\text { vahue }\end{array}$} \\
\hline & & & as & $\begin{array}{l}\text { Tid } \\
\text { pu }\end{array}$ & $\begin{array}{l}\text { lak } \\
\text { as }\end{array}$ & & Puas & & $\begin{array}{l}\text { dak } \\
\text { las }\end{array}$ & & $\mathrm{Pu}$ & uas & & as & \\
\hline & & $f$ & $\%$ & $\mathrm{f}$ & $\%$ & & f $\%$ & f & $\%$ & & $\mathrm{f}$ & $\%$ & 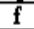 & $\%$ & \\
\hline 1 & $\begin{array}{l}\text { Pendidikan } \\
\text { - Rendah } \\
\text { - Tinggi }\end{array}$ & $\begin{array}{l}3 \\
9\end{array}$ & 23 & $\begin{array}{c}8 \\
30\end{array}$ & $\begin{array}{l}73 \\
77\end{array}$ & 0,774 & $\begin{array}{cc}0 & 0 \\
5 & 11\end{array}$ & 40 & $\begin{array}{l}100 \\
89\end{array}$ & 0,432 & $\begin{array}{l}2 \\
3\end{array}$ & $\begin{array}{c}25 \\
7\end{array}$ & 39 & $\begin{array}{l}75 \\
93\end{array}$ & 0.12 \\
\hline
\end{tabular}

\begin{tabular}{|c|c|c|c|c|c|c|c|c|c|c|c|c|c|c|c|c|}
\hline 2 & $\begin{array}{l}\text { Jenis kelamin } \\
\text { - Perempuan } \\
\text { - Laki-laki }\end{array}$ & $\begin{array}{l}4 \\
8\end{array}$ & $\begin{array}{l}15 \\
35\end{array}$ & $\begin{array}{l}23 \\
15\end{array}$ & $\begin{array}{l}85 \\
65\end{array}$ & 0.99 & $\begin{array}{l}2 \\
3\end{array}$ & $\begin{array}{c}6 \\
16\end{array}$ & $\begin{array}{l}29 \\
16\end{array}$ & $\begin{array}{l}94 \\
84\end{array}$ & 0.285 & $\begin{array}{l}4 \\
1\end{array}$ & $\begin{array}{c}16 \\
4\end{array}$ & $\begin{array}{l}21 \\
24\end{array}$ & $\begin{array}{l}84 \\
96\end{array}$ & 0.157 \\
\hline 3 & $\begin{array}{l}\text { Urour } \\
\text { - Dewasa } \\
\text { awal } \\
\text { - Dewasa } \\
\text { akhir }\end{array}$ & 7 & $\begin{array}{l}25 \\
23\end{array}$ & $\begin{array}{l}15 \\
23\end{array}$ & $\begin{array}{l}75 \\
77\end{array}$ & 0.000 & $\begin{array}{l}1 \\
4\end{array}$ & $\begin{array}{l}8 \\
11\end{array}$ & $\begin{array}{l}11 \\
34\end{array}$ & $\begin{array}{l}92 \\
89\end{array}$ & 0.000 & $\begin{array}{l}1 \\
4\end{array}$ & $\begin{array}{c}6 \\
13\end{array}$ & $\begin{array}{l}17 \\
28\end{array}$ & $\begin{array}{l}94 \\
87\end{array}$ & 0.000 \\
\hline
\end{tabular}

Berdasarkan tabel 1 bahwa dari ketiga rumah sakit kepuasan pasien di dapatkan Hasil uji chi-square hubungan umur pasien dengan mutu pelayanan keperawatan di rumah sakit $\mathrm{Y}, \mathrm{R}, \mathrm{I}$ di dapat $p$-value $0,000<0.05$ maka terdapat hubungan yang bermakna antara umur dengan mutu pelayanan keperawatan di rumah sakit $Y, R$, I.

Hubungan pendidikan terhadap mutu pelayanan di rumah sakit Yos, RSUD, RS yarsi didapatkan $p$-value (0.774), (0,432), (0.123) > 0.05 maka tidak terdapat hubungan antara pendidikan dengan mutu pelayanan keperawatan di rumah sakit Yos, RSUD, RS yarsi di kota Padang.

Tabel 2. Perbandingan Kepuasan Pasien Terhadap Mutu Pelayanan Keperawatan

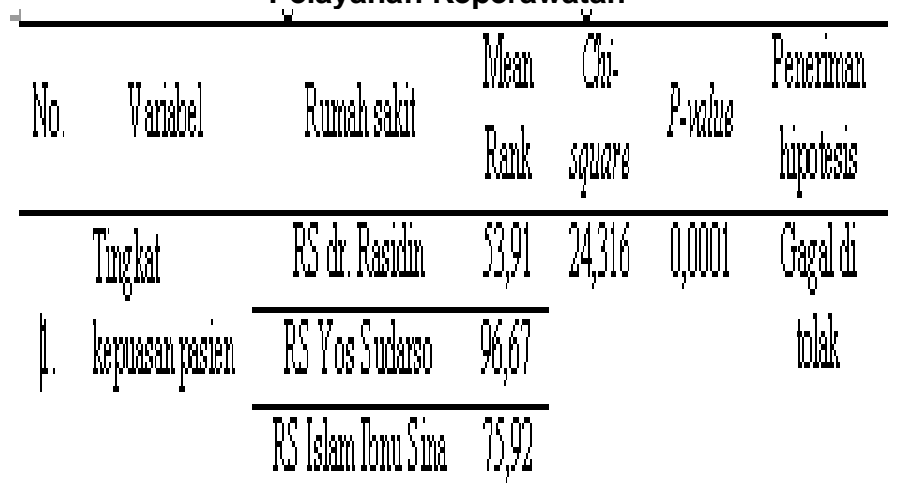

Berdasarkan tabel 2 dapat dilihat bahwa pada tingkat kepuasan pasien di Rumah Sakit $\mathrm{R}, \mathrm{Y}$, dan I nilai probabilitas atau $p$-value $=0,0001<0,05$ maka Ho di tolak. Untuk nilai chi-square hitung didapatkan 24,316 > chi-square tabel $=5,991$ yang menunjukkan bahwa terdapat perbedaan kepuasan pasien di Rumah Sakit R, Y, dan I Kota Padang. Pada nilai Mean Rank didapatkan Rumah Sakit R 53.91, Rumah sakit Y nilai Mean Rank didapatkan 96.67 dan Ruma Sakit I nilai Mean Rank didapatkan 75.92. Dapat disimpulkan bahwa ada perbedaan kepuasan antara ketiga rumah sakit. Dimana Rumah Sakit $Y$ kepuasan pasien terhadap mutu pelayanan keperawatan di atas standar kepuasan pasien sedangkan Rumah Sakit R dan I di bawah standar kepuasan pasien.

\section{Pembahasan}

Hasil penelitian di dapatkan perbedaan kepuasan pasien terhadap mutu pelayanan keperawatan. dari ketiga rumah sakit. Dalam hal ini untuk penilaian kepuasan pasien tersebut di dapatkan nilai tertinggi pada rumah sakit $Y$, sedangkan nilai terendah pada Rumah Sakit R.

Dilihat dari karakteristik ketiga rumah sakit tersebut merupakan rumah sakit tipe $\mathrm{C}$ yang mana ketiga rumah sakit tersebut menerima rujukan untuk BPJS. Walaupun ketiga rumah sakit tersebut tipe nya sama tetapi untuk Rumah Sakit $\mathrm{R}$ di kelola oleh pemerintah sedangkan untuk rumah sakit $Y$ dan I milik swasta (Profil Kesehatan Sumatera Barat, 2012). Dalam hal ini peneliti melihat kenapa nilai tertinggi berada pada rumah sakit swasta karena pasien beranggapan pelayanan yang diberikan oleh rumah sakit swasta lebih baik dari rumah sakit pemerintah. Padahal kalau dilihat untuk tipe rumah sakit yang sama maka standar pelayanannya tentu sama yang diberikan, tetapi kenyataanya di lapangan berbeda.

Dilihat dari tiga rumah sakit tersebut kepala ruangan dalam memberikan asuhan keperawatan kepada pasien terlebih dahulu merencanakan apa tindakan keperawatan untuk kesembuhan pasien dan tidak beranjak dari kolaborasi dengan dokter. Di mana setiaap pagi kepala ruangan mengadakan overan dinas dengan perawat diruangan. Overan dinas yang dilakukan untuk melihat kemajuan pasien dan apa tindak lanjut berikutnya terhadap kesembuhan pasien. Selanjutnya kepala ruangan menanyakan kepada perawatapakah ada permasalahan pada pasien. Permasalahan yang timbul pada pasien terhadap perawat akan menyebabkan pasien tidak puas terhadap rumah sakit dan akan berdampak kepada mutu pelayanan keperawatan.

Perbedaan yang didapatkan pada ke tiga rumah sakit ini di lihat dari lima dimensi Rumah sakit $\mathrm{R}$ dan I pasien merasakan tidak puas rata-rata pada dimensi keandalan. Dimana pasien merasakan perawat dalam memberikan pelayanan keperawatan tidak tepat waktu dan perawat tidak memberikan informasi yang jelas terhadap hal yang dipatuhi dan yang dilarang untuk kesembuhan pasien.

Pada Rumah Sakit $Y$ pasien rata-rata merasakan puas terhadap kelima dimensi dimana Rumah Sakit dalam memberikan pelayanan keperawatan sesuai dengan apa yang diinginkan pasien dan pasien 
merasakan nyaman terhadap lingkungan rumah sakit dimana rumah sakit menentukan jam bezuk keluarga pasien dan aturan yang berlaku pada rumah sakit.

Dilihat dari tiga rumah sakit tersebut untuk nilai mean rank yang rendah berdampak pada kunjungan pada rumah sakit tersebut akan menurun dan berkurang. Untuk nilai mean rank yang tinggi agar tetap mempertahankan, meningkatkan lagi pelayanan yang diberikan kepada pasien.

\section{SIMPULAN}

Dari ketiga rumah sakit didapatkan untuk Rumah Sakit R, Y, I sebagian besar umurnya yaitu dewasa akhir. Jenis kelamin sebagian besar dari ketiga rumah sakit berjenis kelamin perempuan, untuk pendidikan dari ketiga rumah sakit sebagian besar perpendidikan tinggi.

Dari ketiga rumah sakit di dapatkan untuk Rumah Sakit R hampir seluruhnya $(10 \%)$ responden mengatakan puas. Rumah sakit $\mathrm{Y}$ hampir seluruhnya (24\%) responden mengatakan puas. Rumah sakit I hampir seluruhnya (10\%) responden mengatakan puas.

Dari ketiga rumah sakit didapatkan nilai $p$-value $0,000<$ maka Ho di tolak dan terdapat perbedaan tingkat kepuasan pasien terhadap mutu pelayanan keperawatan di tiga rumah sakit di kota padang.

\section{DAFTAR PUSTAKA}

Arikunto, (2010). Prosedur Penelitian. Jakarta: Rineka Cipta

Laporan tahunan, 2014. Data Kepegawaian RSUD dr Rasidin Padang. Padang.

Laporan tahunan, 2014. Data Kepegawaian Rumah sakit Yos Sudarso Padang. Padang

Laporan tahunan, 2014. Data Kepegawaian Rumah Sakit Islam Ibnu Sina Padang. Padang.

Dahlan, Sopiyudin, 2012. Statistik Untuk Kedokteran dan Kesehatan. Salemba Medika: Jakarta.

Data rumah sakit online kota Padang, 2014 http://sirs.buk.depkes.go.id/rsonline/Peta list.php? goto=1 (data rumah skit kota padang) diakses tanggal 16 September 2014

Gillies, D.A 1994. Nursing Manajemen: A Sistem Approach. (3ed) Philadelphia : WB sauders Company.

Notoadmodjo 2010. Metodologi penelitian kesehatan. Jakarta: Rineka Cipta

Nursalam, 2011. Konsep dan Penerapan Metodologi Penelitian IImu Keperawatan Pedoman Skripsi, Tesis, Dan Instrumen Penelitian Keperawatan, Salemba Medika: Jakarta

Nursalam, 2012. Manajemen Keperawatan Aplikasi dalam Praktik Keperawatan Profesional, Salemba Medika: Jakarta

Profil Kesehatan Sumatera Barat, 2012 